\title{
Management of Hepatocarcinoma with Celecoxib and Pentoxifylline: Report of Three Cases
}

\author{
Angel $\mathrm{MJL}^{1,2}$, Samuel $\mathbf{R F}^{2}$, Paulina $\mathbf{R V}^{2}$, Angel $\mathbf{M J P}^{1}$, Georgina $\mathbf{H F}^{3}$ and Alejandro $\mathbf{B C}^{3,4^{*}}$ \\ ${ }^{1}$ Hospital "Valentín Gómez Farías" (ISSSTE), Zapopan, Jalisco, México \\ ${ }^{2}$ Centro Universitario de Ciencias de la Salud (CUCS), Universidad de Guadalajara, México \\ ${ }^{3}$ División de Inmunología, Centro de Investigación Biomédica de Occidente (CIBO-IMSS), México \\ ${ }^{4}$ Centro Universitario de los Altos (CUALTOS), Universidad de Guadalajara, México
}

*Corresponding author: Alejandro BC, Centro de Investigación Biomédica de Occidente del IMSS, Sierra Mojada 800, Col Independencia, CP 44340, Guadalajara, Jalisco. Mexico, Tel: (5233) 36170060 ext. 31926; E-mail: abravocster@gmail.com

Received date: October 09, 2018; Accepted date: October 30, 2018; Published date: November 05, 2018

Copyright: $\odot 2018$ Alejandro BC, et al. This is an open-access article distributed under the terms of the Creative Commons Attribution License, which permits unrestricted use, distribution, and reproduction in any medium, provided the original author and source are credited.

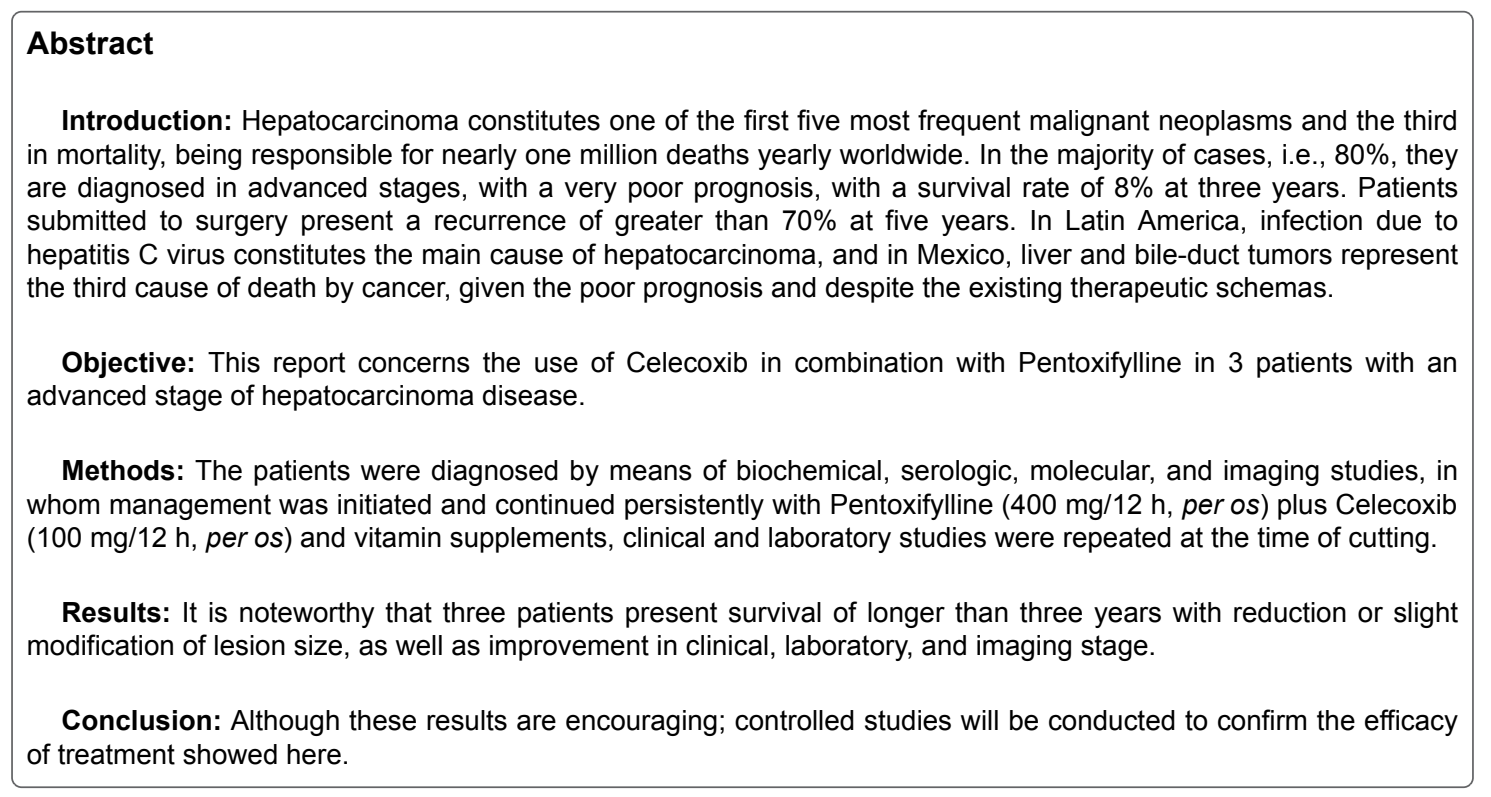

Keywords: Celecoxib; Pentoxifylline; Hepatocarcinoma treatment

\section{Introduction}

Hepatocellular carcinoma (HCC) is the most common liver tumor. It represents $85 \%$ of cancers of the liver, constitutes one of the first five most frequent malignant neoplasms, and is the third cause of death due to cancer worldwide [1]. The annual incidence of HCC at the world level ranges from 500,000 to $1,000,000$ cases [2]. It entertains a predominance of great geographic variability in regions of Asia and Africa, being responsible for 750,000 and 1 million deaths yearly [2,3]. In México, malignant tumors represent the third cause of death with approximately 48,255 each year, among which $12 \%$ correspond to tumors of the liver and the bile ducts, occupying third place [4].

Eighty percent of cases of hepatocarcinoma are associated with chronic infection due to hepatitis B or C virus [5]. Hepatitis C Virus (HCV) the main factor in Latin America, the U.S., and Europe, whereas Hepatitis B Virus (HBV), is the principal factor in Asian and North African regions [6,7]. Other etiological factors including genetic diseases such as tyrosinosis, hemochromatosis, Wilson disease, a1antitrypsin deficiency, or immunological causes such as chronic autoimmune hepatitis or primary biliary cirrhosis, among other entities that have been scarcely studied [8]. In Mexico, the majority of cases of HCC appear as a consequence of hepatic cirrhosis associated with HCV [4]. However, in recent years, an increase in the incidence of cases of HCC associated with the fatty liver-related metabolic syndrome has been observed $[8,9]$.

In order to carry out the diagnosis of HCC, there are useful tests for the scrutiny of patients and groups of patients at risk, among whom the following are found: serum alpha-fetoprotein (AFP) levels with a sensitivity of $25 \%-65 \%$ for early detection. However, due to that in up to $30-50 \%$ of cases, AFP may not be found elevated, this is not recommended as a sole means of detection [10]. It has been demonstrated that this added to ultrasonography (USG) showing an increases its sensitivity. By itself, USG possesses a sensitivity of $65 \%$ and a specificity of $95 \%$, which at present render its consideration as the first choice for scrutiny $[11,12]$. However, radiological tests comprise the main tool for the diagnosis of HCC due to their diagnostic usefulness and follow-up [13-16]. Confirmation will depend on its vascular behavior observed in the tomography or the contrast magnetic resonance imaging (MRI), appreciating four points comprising the following: 1) simple; 2), arterial; 3) venous, and 4) portal. Confirmation is considered when a lesion is found that is larger than $1 \mathrm{~cm}$ with arterial reinforcement and rapid venous emptying, by 
computerized axial tomography (CAT) or nuclear magnetic resonance (NMR) without the need for confirmatory biopsy. On finding a lesion larger than $1 \mathrm{~cm}$ with classic vascular behavior in an initial study by means of CAT or NMR, a second imaging study should be performed, the latter being CAT if NMR is performed first or vice versa; in the case of the second study detecting classic vascular behavior, diagnosis will be performed without the need for a biopsy. In the case of there being a doubt and if a lesion larger than $1 \mathrm{~cm}$ with classic vascular behavior is not found, a biopsy will be conducted to arrive at a definitive diagnosis [13].

Despite existing therapeutic measures such as chemoembolization, alcoholization, chemotherapy, surgical treatment, and liver transplant in advanced cases, HCC it has a poor prognosis. This is maybe due, to more of the cases are diagnosed in advanced stages with a 3-year survival rate of only $8 \%$ [14-16]. The majority of treatment options is costly and requires specialized centers. Currently, Sorafenib is treatment-of-choice in patients with advanced HCC that cannot be resected. This drug is a multikinase inhibitor (serine-threonine, RAF-1, and B-RAF), as well as of the receptors of threonine activity of vascular endothelial growth factor receptor (VEGFR 1,2 and 3), and plateletderived growth factor receptor $\beta$ (PDGFR- $\beta$ ). VEGF is one of the most relevant and crucial angiogenic factors for the persistent proliferation of tumor cells. Therefore, its inhibition would explain the diminution of tumor growth and angiogenesis, in that it acts to inhibit the targets in the tumor cell (CRAF, BRAF, V600E BRAF, KIT, and FL3) and the tumor vasculature (CRAF, VEGFR-2, VEGFR-3, and PDGFR- $\beta$ ) [17]. However, it exerts adverse effects such as diarrhea, weight loss, handfoot syndrome, and hypophosphatemia, it is expensive, and patients present an average survival of 10.7 months with the treatment [18].

Given that present-day treatments are not sufficiently effective, other strategies have been sought, based on the concept of chemotherapy with rational molecular bases [17-19].

In this regard, we can mention that pentoxifylline (PTX) 1- [5oxohexyl] -3, 7-dimethyl xanthine] a non-specific phosphodiesterase inhibitor that has been utilized routinely for circulatory diseases during $>20$ years [20]. PTX is a potent inhibitor of tumor necrosis factor alpha (TNF- $\alpha$ ), and Nuclear Factor-kappa B (NF- $\kappa$ B), has been showing sensitizes tumor cells to the toxic action of different antitumor drugs in experimental murine models and has been employed successfully in humans [21-24]. In this same respect, we are able to mention that Cyclooxygenase (COX) is a key enzyme for the synthesis of prostaglandins. It is known that $\mathrm{COX}$ is a constitutive enzyme (COX-1) but can be inducible (COX-2). The inducible form COX-2 is undetectable at the baseline level in the majority of tissues; however, it can rise to between 10 and 80 times in the presence of inflammatory processes and in different cancer types such as colon, breast, prostate, gallbladder, and lung [25]. It is found constitutively in the tissues, but also, inflammatory agents or processes can induce its generation; this enzyme is denominated COX-2, and it plays an essential role in the development of HCC. It has been considered that its overexpression is related to hepatocarcinogenesis and angiogenesis [25,26].

Currently, it is known that COX-2 is selectively inhibited by Celecoxib, impeding the formation of prostaglandins from arachidonic acid. In prior studies, it was suggested that COX-2 inhibitors could inhibit the growth of tumor cells in animal models or patients $[27,28]$ because, on inhibiting COX-2, antiangiogenic, antifibrotic, and proapoptotic effects have been observed, given that it participates in the production of VEGF factors. It also affects the cytosine production like InterLeukin (IL)- $1 \alpha$ and $\beta$, TNF- $\alpha$, signaling pathways such as $\mathrm{NF}-\kappa \mathrm{B}$, and proteosome inhibitors (PI), and inhibits genes such as BCL-2, among other effects [28]. Its employment has begun to extend itself to other fields beyond its described initially anti-inflammatory role. In this manner, its daily administration during six months at a dose of $800 \mathrm{mg} /$ day in patients with familial adenomatous polyposis was observed in significant reductions of colorectal polyps, and it has been employed with encouraging results in lung cancer $[29,30]$ and HCC. In this study, we present the report of three cases of patients with hepatocarcinoma who were treated for the first time with a combination of PTX+Celecoxib, finding interesting results, principally in relation with survival.

\section{Clinical Cases and Methods}

The 3 patients were selected randomly on the Gastroenterology Service of the Valentin Gómez Farías Hospital, ISSSTE, Guadalajara, Jal. Méx.

\section{Case 1}

A 58 years old male, whose origin and residence was Guadalajara, Jalisco, Mexico. He was seen at the beginning due to his presenting nausea, icteric, asthenia, adynamia, and grade I-II encephalopathy, an antecedent of positive alcoholism during 47 years, and a diagnosis of Child-Pugh score C 18 months prior to his consultation, with negative serology for hepatitis B and C virus (Table 1). It was decided to admit the subject and imaging studies were performed, such as echosonogram and tomography, finding a focal lesion in right lobe of 8 x $8 \mathrm{~cm}$, circular in form, suggestive of HCC. Thus, magnetic cholangioresonance was conducted revelated a liver increased in size, 8 x $8 \mathrm{~cm}$ tumor was found in right lobe, with hypointense zones in T1 and hyperintense in $\mathrm{T} 2$ on the application of magnetic contrast, with highly vascularized lesion, with arterial reinforcement and rapid venous emptying with irregular necrotic zones in its interior (Figure 1A), without evidence of metastasis in the liver.

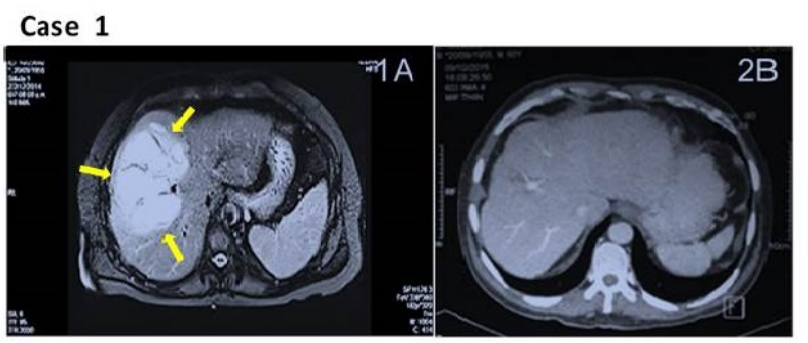

Figure 1A: Magnetic resonance prior to treatment showing a tumor in the right lobe of $8 \times 8 \mathrm{~cm}$, with arterial reinforcement and rapid venous emptying, with irregular areas of necrosis.

Figure 1B: Computerized Axial Tomography of the liver taken 48 months after the start of treatment with Pentoxifylline and Celecoxib, which shows almost ablation of the tumor. 
Citation: Angel MJL, Samuel RF, Paulina RV, Angel MJP, Georgina HF, et al. (2018) Management of Hepatocarcinoma with Celecoxib and Pentoxifylline: Report of Three Cases. J Clin Exp Pharmacol 8: 255. doi:10.4172/2161-1459.1000255

Page 3 of 6

\begin{tabular}{|c|c|c|c|c|c|c|c|c|c|}
\hline \multirow[b]{2}{*}{ Tests } & \multicolumn{2}{|l|}{ Case 1} & \multirow[b]{2}{*}{$\Delta \%$} & \multicolumn{2}{|l|}{ Case 2} & \multirow[b]{2}{*}{$\Delta \%$} & \multicolumn{2}{|l|}{ Case 3} & \multirow[b]{2}{*}{$\Delta \%$} \\
\hline & Base-line & Post treatment & & Base-line & Post treatment & & Base-line & Post-treatment & \\
\hline ALT (IU/dL) & 115 & 19 & -83 & 102 & 68 & -33 & 42 & 12 & -71 \\
\hline AST (IU/dL) & 192 & 18 & -90 & 102 & 46 & -55 & 16 & 31 & 93 \\
\hline AP (IU/dL) & 222 & 165 & -25 & 306 & 239 & -21 & 260 & 144 & -44 \\
\hline BT (mg/dL) & 3.6 & 0.7 & -80 & 3 & 0.8 & -73 & 1.8 & 2.5 & 39 \\
\hline $\mathrm{TP}(\mathrm{mg} / \mathrm{dL})$ & 5.6 & 7.3 & 30 & 6.1 & 6.6 & 8 & 7 & 7.5 & 6 \\
\hline Albumin (g/dL) & 1.8 & 4.1 & 127 & 3.3 & 3.2 & -3 & 3.3 & 3.9 & 20 \\
\hline AFP $\mu \mathrm{I} / \mathrm{L}$ & 240 & 2.9 & -98 & 47.7 & 25.2 & -53 & 4 & 2.9 & -29 \\
\hline Tumor size $(\mathrm{mm})$ & $80 \times 80$ & 0 & -100 & $32 \times 23$ & $30 \times 32$ & 31 & $40 \times 40$ & $48 \times 46$ & 38 \\
\hline
\end{tabular}

Table 1: Serum markers before and after 48 months of treatment; IU: International Units; ALT: Alanine Amino Transferase; AST: Aspartate Amino Transferase; TP: Total Proteins; BT: Total Bilirubins; AP: Alkaline Phosphate; AFP: Alpha-fetoprotein.

\section{Case 2}

A 86 years old female, coming from Tapalpa, Jalisco, México, a homemaker, and who had been treated during 13 years for hepatic cirrhosis presenting jaundice, disorientation, grade-1 ascites, and grade-2 esophageal varicose veins, with an antecedent of Child-Pugh C-stage 1b-genotype HCV (Table 1). The HCV was detected 17 years ago and the treatment was initiated with Pegylated Interferon (180 $\mu \mathrm{g} / 7$ day's c.s. and Ribavirin $400 \mathrm{mg} / 8 \mathrm{hr}$ per os for 54 weeks and displaying a sustained viral response until today. Five years later, she was monitored with biochemical, molecular, and echosonographic studies. The patient developed a tumor in the right lobe, $32 \times 23 \times 23$ $\mathrm{mm}$, observed in contrast CAT with arterial reinforcement with rapid venous emptying (Figure 2A), with which HCC was diagnosed, and the proposed treatment was started, with anti-ammonium measures and primary esophageal-varicose veins prophylaxis.

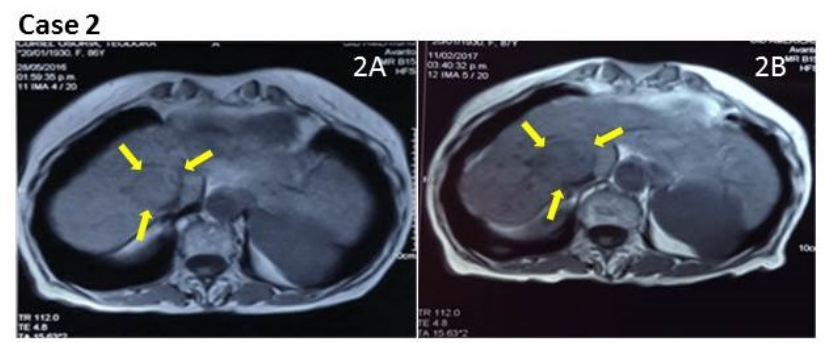

Figure 2A: Abdominal Magnetic Resonance, evidencing an infiltrative lesion in the right hepatic lobe, which can be seen at 32 $\mathrm{mm} \times 23 \mathrm{~mm} \times 23 \mathrm{~mm}$ at diagnosis.

Figure 2B: Abdominal Magnetic Resonance, evidencing infiltrative lesion in the right hepatic lobe of $28 \mathrm{~mm} \times 28 \mathrm{~mm} \times 28 \mathrm{~mm}$ to the control at 48 months of treatment with Pentoxifylline and Celecoxib.

\section{Case 3}

A 65-year-old male, a teacher by profession, from the Mexican state of Michoacán, with an antecedent of alcoholism of more than 35 years. The patient presented for consultation with abdominal pain, weight loss, the antecedent of disorientation, and with serologies for negative hepatitis $\mathrm{B}$ and $\mathrm{C}$ virus, with a diagnosis of Child-Pugh C-stage alcoholism-associated cirrhosis, grade-II esophageal varicose veins, and severe hypertensive gastropathy (Table 1). After seven years of control and with compensated cirrhosis, without of evidence of tumor, with the development of imaging of the liver and bile ducts that evidenced tumor of $39 \times 39 \mathrm{~mm}$ in the right lobe with arterial reinforcement and rapid venous emptying in segments VII and VIII (Figure 3A).

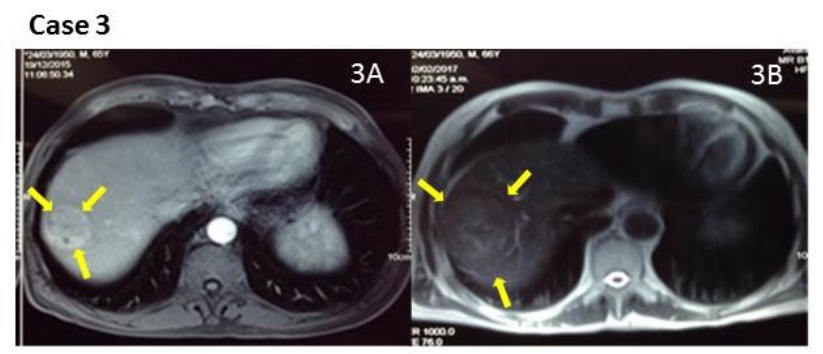

Figure 3A: Abdominal Magnetic Resonance, evidencing infiltrative lesion in the right hepatic lobe, which can be seen at $39 \mathrm{~mm} \times 39$ $\mathrm{mm}$ at diagnosis.

Figure 3B: Abdominal Magnetic Resonance, evidencing infiltrative lesion in the right hepatic lobe of $55 \mathrm{~mm} \mathrm{x} 48 \mathrm{~mm}$ at the control after 48 months of treatment with Pentoxifylline and Celecoxib.

The patients were treated with PTX at $400 \mathrm{mg}$ every $12 \mathrm{hr}$, per os, in combination with Celecoxib $100 \mathrm{mg}$ every $12 \mathrm{hr}$, per os, in a sustained manner, during the entire observation period.

For analysis of the results, we calculated $\Delta \%$, which signifies the percentage of increase or decrease in relation to the baseline values, considering $\geq 30 \%$ as significant. 


\section{Ethical Considerations}

The three patients signed an informed consent agreement and the protocol was approved by the Scientific and Ethical Committee, at the Hospital "Valentín Gómez Farías", ISSSTE with the number: ISSSTE/CEI/247/2014.

\section{Results}

In regard to the clinical results, it is noteworthy that the three patients exhibited a survival of 48 months after treatment initiation, together with clinical and laboratory improvement; therefore, at 4 years, the three patients were cataloged according to Child-Pug classification criteria in state $\mathrm{A}$, indicating functional improvement of the liver disease. The latter is depicted in Table 1, in which it is possible to observe that all of the patients, at the end of follow-up, presented normal or very near normal values of hepatic enzymes alanine aminotransferase (ALT) and aspartate aminotransferase (AST), which means a diminution of the initial value of the hepatic enzymes for ALT of 115,102 and $42 \mathrm{IU}$ (international units)/dL for the case 1, 2 and respectively, and 48 month after we observed a diminution of $\Delta \%=-83 \%,-33 \%$, and $-71 \%$ for the first, second and third patient respectively. With respect to AST the serum concentration at the begin of the treatment was case $1=192 \mathrm{IU} / \mathrm{dL}$, case $2=102 \mathrm{IU} / \mathrm{dL}$ and case $3=16 \mathrm{IU} / \mathrm{dL}$ and at the end of treatment, we observed the same behavior toward normalization, signifying an important diminution of the initial levels of this enzyme, reaching $\Delta \%=-90 \%,-55 \%$, and $-93 \%$, respectively, for the three cases. The alkaline phosphatase (AP) baseline determination shown values of 222, 306 and $260 \mathrm{IU} / \mathrm{dL}$ for the case 1,2 and 3 respectively and at the end of the treatment we observed in the 3 cases a diminution of $\Delta \%=-25$ and $\Delta \%=-21$ for cases 1 and 2 and $\Delta \%=-44$ for the third case. In relation to the serum proteins, only in the first case did we observe $\Delta \%=30 \%$ on increasing from $5.6 \mathrm{mg} / \mathrm{dL}$ to $7.3 \mathrm{mg} / \mathrm{dL}$ at the end of the observation; in the remaining two cases, there was practically no variation. In relation to albumin, we observed, in the first as well as in the third case, an increase in albumin that, at the beginning of the study, presented baseline values of 1.8 (case 1) and $3.3 \mathrm{~g} / \mathrm{dL}$ (case 3), observing, at the end of the study, increases of $\Delta \%=127 \%$ and of $\Delta \%=20 \%$, respectively; however, the second case did not exhibit a modification of the serum concentration of albumin $(3.3 \mathrm{~g} / \mathrm{dL}$ at the beginning and of $3.2 \mathrm{~g} / \mathrm{dL}$ at the end). As expected, at study initiation, the three cases presented an elevated number of total bilirubin 3.6, 3.0, and $1.85 \mathrm{mg} / \mathrm{dL}$, respectively and, significantly, we observed in the first two cases a significant diminution of total bilirubin, with $\Delta \%=-80 \%$ for the first case, $\Delta \%=-73 \%$ for the second case, and the third case, in contrast, shown a different behavior, because at the beginning, it showed a total bilirubin level of $1.85 \mathrm{mg} / \mathrm{dL}$ and at the end, one of $2.58 \mathrm{mg} / \mathrm{dL}$, representing $\Delta \%=39 \%$. Finally, follow-up of Alpha-fetoprotein (AFP) marked the tumor prognosis of HCC, in that at the beginning, the three cases presented a considerable elevation of this marker (240.0 $\mu \mathrm{g} / \mathrm{L}, 47.7 \mu \mathrm{g} / \mathrm{L}$, and $4.0 \mu \mathrm{g} / \mathrm{L}$, respectively) and significant diminution at the end of the study, i.e., $\Delta \%=-98 \%$ for the first case, $\Delta \%=-53 \%$ for the second, and $\Delta \%=-29$ for the third case. In relation to tumor size, it is noteworthy that case 1 at 48 months of treatment presented a tumor of $80 \times 80 \mathrm{~mm}$ that had practically disappeared (Figure 1B), while case 2 (Figure $2 \mathrm{~B}$ ) and 3 (Figure $3 \mathrm{~B}$ ) presented a different behavior, since their tumors grew $(\Delta \%=31 \%$ and $38 \%$, respectively).

\section{Discussion and Conclusion}

In 1863, Rudolph Virchow described a relationship between chronic inflammation and cancer [31], at present this concept is considered very important in carcinogenesis as well as in tumor development in terms of HCC [25]. We present three cases of HCC treated with PTX and Celecoxib, with very favorable results both in the clinic and in the laboratory. This is because the three cases presented statistically had few or no probabilities of surviving more than 3 months; however, the schema proposed with PTX plus Celecoxib, appears to positively influence the natural history of the disease, increasing the survival of the patients to nearly 4 years, meaning an increase in months of $\Delta \%=1500 \%$. The latter is supported by significant clinical improvement of the three patients; in this manner, they improved from the Child-C scale to the Child-A scale, while in hepatic enzymes in terms of ALT, the three patients improved significantly, with practically normal values. However, for AST in cases 1 and 3, this returned to normal post-treatment values, and in case 2 , the diminution of this enzyme reduced considerably $(\Delta \%=-55 \%)$, remaining slightly elevated. In relation to the AP in the 1 and 2 cases, it is noted a not significant diminution of the serum levels of this enzyme contrary the case 3 shows a significant diminution of the AP $(\Delta \%=-44 \%)$. In relation to hepatic parameters determined here, it is important to remember that the recovery of them is spite to the previous hepatic disease. With regard to the albumin, it is noteworthy that cases patients 2 and 3 presented numbers for albumin within normal ranges and these were not modified; however, case 1 showed significant recovery on the normalization of serum concentration. Taken together, these results show a part of the efficiency of the proposed treatment and, on the other hand, the lowering of its toxicity, since it practically improved the hepatic function, which is one of the first functions altered when there is inflammatory or degenerative damage. The latter is also supported by the fact that none of the patients withdrew from treatment; only slight adverse effects were reported, such as nausea and vomiting, which were resolved without the need to suspend the treatment.

On the other hand, what supports the proposed treatment's efficiency and that is highly important to consider, is that the direct tumor data are in agreement with the latter, in that, in cases 1 and 3, the concentration of the HCC marker, the AFP returned to normal parameters, while in case 2 , despite a significant reduction, an elevation continued to be demonstrated with respect to normal values, observing a significant diminution in the first two cases $(\geq 30 \%)$, and in the third, only $1 \%$ was lacking to consider it significant. However, only one patient showed tumor regression registered by NMR. This apparent lack of correlation between NMR and AFP may be explained since all the 3 patients showed clinically and laboratory improvement which were also supported by the survival of patients. Keeping the above mentioned in mind, there is not always a correlation between clinical state and the serum level of AFP. In addition, it is reported that 30 to $50 \%$ of patients with HCC show normal serum levels of AFP [32].

Finally, in this same regard, something that calls our attention is that case-patient 1 at 48 months of treatment presented a tumor of initially $80 \times 80 \mathrm{~mm}$ that practically disappeared, while in case 2 and 3 a moderate increment was evidenced in tumor size. The latter is important in the three cases, suggesting a diminution in the tumor's aggressively, in that the patients greatly exceeded the life expectancy, the most important and relevant component.

On the other hand and independently of the survival, the fact that the three patients did not display the same behavior in relation to some 
parameters may be due to several factors such as pharmacogenetics, molecular and histological characteristics of the tumors as well as other factors such as lifestyle and, previous history. Further studies can give light for a potential marker of individualization.

To our knowledge, this is the first report showing in which the combination of PTX+Celecoxib is employed for the treatment of HCC, and the results, albeit small, are encouraging. Recently, it was suggested that NF- $\mathrm{KB}$ plays a role in the mechanism of oncogenesis in HCC, as a regulator of the transcription of cellular functions, including, adhesion, the immune response, invasion, differentiation, surviving genes, and cellular proliferation, as well as of apoptosis $[33,34]$.

On its part, PTX is a methylxanthine possessing anti-inflammatory effects that inhibit the NF- $\mathrm{BB}$ factor. Antitumor effects have been found per se, and they potentialized chemotherapy and radiotherapy $[19,21]$ and has been reported in leukemic children with encouraging results and minimal adverse effects, such as abdominal pain, nausea, vomiting, and diarrhea, the latter presenting in $3 \%$ of patients $[22,35]$. Thus, it was decided to use PTX as a treatment alternative.

Our results are in agreement with those in the literature. Therefore, Celecoxib with other drugs appears to be useful. In this regard, Jie Cuiy et al. demonstrated that the use of non-steroidal anti-inflammatory drugs (NSAID's) reduces the incidence of HCC by $37 \%$ and reduces mortality by up to $51 \%$ in patients with chronic liver diseases [36]. Bassiouny Ahmad et al. carried out a comparative study of patients with HCC. The control group was treated with 5-FU and Cyclophosphamide, while the study group received 5-FU, Cyclophosphamide, and Celecoxib. It was observed that the patient who received Celecoxib presented an important regression in tumor size through activation of the caspase- 3 pathway and diminution of the pro-angiogenic factors [37]. The combination of Celecoxib+Sorafenib demonstrated to be more efficient in reducing tumor size than Sorafenib alone [38], involving anti-proliferative and pro-apoptotic mechanisms, activating the ERK 1/2 signaling pathway and inhibiting the MEK/ERK pathway [37]. Similarly, the employment of Celecoxib + Interferon (IFN $\gamma$ ) showed good results experimentally, even favoring the immune response on increasing the number of macrophage phenotype-M1 [39].

In terms of the mechanism of action of the combination of drugs employed, it is obvious that it is complex; nonetheless, it is worthwhile to consider that there are multiple signaling pathways that are found involved in the development of HCC, such as epidermal and endothelial growth factors, platelet-derived growth factors, insulin-like growth factors, activation of protein kinase, $\beta$-catenin, phosphatidylinositol 3-kinase, and interleukin 6 , as well as transcription factors such as STAT3, NF- $\mathrm{kB}$ and Hedgehog, which eventually give rise to resistance to apoptosis, promote cellular proliferation, and stimulate angiogenesis, invasion, and the metastasis of tumor cells [40-42]. On its part, Celecoxib possesses antiinflammatory, anti-angiogenic, and pro-apoptotic activity through the inhibition of IL- 6 and the expression of TGF- $\beta$ and metalloproteases- 2 and their receptor, which in turn impedes the activity of JAK 2 and STAT3 [43-45]. The PTX acts in inhibiting NF- $\kappa B$, the secretion of pro-inflammatory interleukins, inhibiting anti-apoptotic BCL-2, BCLXL, MCL-1, and surviving genes expression and the same time inducing pro-apoptotic related genes such as DIABLO, BAK, BAX PUMA NOXA, and FAS, as well as increasing the activity of caspases that are central to the apoptotic process [46].
In conclusion, the combination of PTX+Celecoxib reveals encouraging results, increasing the survival of patients, sustaining, with clinical and laboratory improvements, all of the latter at a low cost and with minimal adverse effects. They support the idea that chemotherapy with rational molecular bases can comprise an excellent alternative in relation to traditional chemotherapy.

\section{References}

1. Kinoshita A, Onoda H, Fushiya N, Koike K, Nishino H, et al. (2015) Staging systems for hepatocellular carcinoma: Current status and future perspectives. World J Hepatol 7: 406-424.

2. Torre LA, Bray F, Siegel RL, Ferlay J, Lortet-Tieulent J, et al. (2015) Global cancer statistics, 2012. CA Cancer J Clin 65: 87-108.

3. Pilar LPRd (2015) Neoplasias hepáticas malignas: 1.a parte. Hepatocarcinoma: papel de la biopsia hepática, estudios de inmunohistoquímica y otros aspectos importantes. Rev Col Gastroenterol 30: 232-242

4. Mendez-Sanchez N, Villa AR, Vazquez-Elizondo G, Ponciano-Rodriguez G, Uribe M (2008) Mortality trends for liver cancer in Mexico from 2000 to 2006. Ann Hepatol 7: 226-229.

5. Perz JF, Armstrong GL, Farrington LA, Hutin YJ, Bell BP (2006) The contributions of hepatitis $\mathrm{B}$ virus and hepatitis $\mathrm{C}$ virus infections to cirrhosis and primary liver cancer worldwide. J Hepatol 45: 529-538.

6. Maucort-Boulch D, de Martel C, Franceschi S, Plummer M (2018) Fraction and incidence of liver cancer attributable to hepatitis B and C viruses worldwide. Int J Cancer 142: 2471-2477.

7. Wang M, Wang Y, Feng X, Wang R, Wang Y, et al. (2017) Contribution of hepatitis $\mathrm{B}$ virus and hepatitis $\mathrm{C}$ virus to liver cancer in China north areas: Experience of the Chinese National Cancer Center. Int J Infect Dis 65: 15-21.

8. Huezo MSG (2014) Consenso mexicano de diagnóstico y manejo del carcinoma hepatocelular. Rev de Gaseroenterología de México 79: 250-262.

9. Cuevas AA, Patrón CA, Méndez-Vivas WR (2015) Hepatocarcinoma en hígado no cirrótico: Presentación de un caso y revisión de la literatura. Evid Med Invest Salud 8: 32-36.

10. Kim JU, Shariff MI, Crossey MM, Gomez-Romero M, Holmes E, et al. (2016) Hepatocellular carcinoma: Review of disease and tumor biomarkers. World J Hepatol 8: 471-484.

11. El-Serag HB, Marrero JA, Rudolph L, Reddy KR (2008) Diagnosis and treatment of hepatocellular carcinoma. Gastroenterology 134: 1752-1763.

12. Erazo-Valle SAA, Arellano-Sotelo J, Barrera-Franco JL, Benítez-Arroyo H (2012) Guía mexicana de tratamiento del hepatocarcinoma avanzado. Gaceta Mexicana de Oncología 11: 1-14.

13. Bruix J, Reig M, Sherman M (2016) Evidence-based diagnosis, staging, and treatment of patients with hepatocellular carcinoma. Gastroenterology 150: 835-853.

14. Jha RC, Zanello PA, Nguyen XM, Pehlivanova M, Johnson LB, et al. (2014) Small hepatocellular carcinoma: MRI findings for predicting tumor growth rates. Acad Radiol 21: 1455-1464.

15. Boas FE, Do B, Louie JD, Kothary N, Hwang GL, et al. (2015) Optimal imaging surveillance schedules after liver-directed therapy for hepatocellular carcinoma. J Vasc Interv Radiol 26: 69-73.

16. Bogaerts J, Ford R, Sargent D, Schwartz LH, Rubinstein L, et al. (2009) Individual patient data analysis to assess modifications to the RECIST criteria. Eur J Cancer 45: 248-260.

17. Ikeda M, Morizane C, Ueno M, Okusaka T, Ishii H, et al. (2018) Chemotherapy for hepatocellular carcinoma: Current status and future perspectives. Jpn J Clin Oncol 48: 103-114.

18. Caroline Randrup HDG, Johann B, Markus W, Nils E (2017) Effects and side effects of using sorafenib and sunitinib in the treatment of metastatic renal cell carcinoma. Int J Mol Sci 18: 1-14.

19. Lerma-Diaz JM, Hernandez-Flores G, Dominguez-Rodriguez JR, OrtizLazareno PC, Gomez-Contreras P, et al. (2006) In vivo and in vitro 
Citation: Angel MJL, Samuel RF, Paulina RV, Angel MJP, Georgina HF, et al. (2018) Management of Hepatocarcinoma with Celecoxib and Pentoxifylline: Report of Three Cases. J Clin Exp Pharmacol 8: 255. doi:10.4172/2161-1459.1000255

Page 6 of 6

sensitization of leukemic cells to adriamycin-induced apoptosis by pentoxifylline. Involvement of caspase cascades and IkappaBalpha phosphorylation. Immunol Lett 103: 149-158.

20. Ward A, Clissold SP (1987) Pentoxifylline. A review of its pharmacodynamic and pharmacokinetic properties, and its therapeutic efficacy. Drugs 34: 50-97.

21. Bravo-Cuellar A, Hernandez-Flores G, Lerma-Diaz JM, DominguezRodriguez JR, Jave-Suarez LF, et al. (2013) Pentoxifylline and the proteasome inhibitor MG132 induce apoptosis in human leukemia U937 cells through a decrease in the expression of Bcl-2 and Bcl-XL and phosphorylation of p65. J Biomed Sci 20: 13.

22. Meza-Arroyo J, Bravo-Cuellar A, Jave-Suarez LF, Hernandez-Flores G, Ortiz-Lazareno P, et al. (2018) Pentoxifylline added to steroid window treatment phase modified apoptotic gene expression in pediatric patients with acute lymphoblastic leukemia. J Pediatr Hematol Oncol 40: 360-367.

23. Ortiz-Lazareno PC, Bravo-Cuellar A, Lerma-Diaz JM, Jave-Suarez LF, Aguilar-Lemarroy A, et al. (2014) Sensitization of U937 leukemia cells to doxorubicin by the MG132 proteasome inhibitor induces an increase in apoptosis by suppressing NF-kappa B and mitochondrial membrane potential loss. Cancer Cell Int 14: 13.

24. Hernandez-Flores G, Bravo-Cuellar A, Aguilar-Luna JC, Lerma-Diaz JM, Barba-Barajas M, et al. (2010) [In vitro induction of apoptosis in acute myelogenous and lymphoblastic leukemia cells by adriamycine is increased by Pentoxifylline]. Presse Med 39: 1330-1331.

25. Chen G, Li X, Yang J, Li J, Wang X, et al. (2016) Prognostic significance of cyclooxygenase-2 expression in patients with hepatocellular carcinoma: a meta-analysis. Arch Med Sci 12: 1110-1117.

26. Koki AT, Masferrer JL (2002) Celecoxib: A specific COX-2 inhibitor with anticancer properties. Cancer Control 9: 28-35.

27. Chavez E, Segovia J, Shibayama M, Tsutsumi V, Vergara P, et al. (2010) Antifibrotic and fibrolytic properties of celecoxib in liver damage induced by carbon tetrachloride in the rat. Liver Int 30: 969-978.

28. Sun YZ, Cai N, Liu NN (2017) Celecoxib down-regulates the hypoxiainduced expression of HIF-1 $\alpha$ and VEGF through the PI3K/AKT pathway in retinal pigment epithelial cells. Cell Physiol Biochem 44: 1640-1650.

29. van Heumen BW, Roelofs HM, Vink-Borger ME, Dekker E, MathusVliegen EM, et al. (2013) Ursodeoxycholic acid counteracts celecoxib in reduction of duodenal polyps in patients with familial adenomatous polyposis: A multicentre, randomized controlled trial. Orphanet J Rare Dis 8: 118.

30. Li Q, Peng J, Liu T, Zhang G (2017) Effects of celecoxib on cell apoptosis and Fas, FasL and Bcl-2 expression in a BGC-823 human gastric cancer cell line. Exp Ther Med 14: 1935-1940.

31. Virchow R (1881) An address on the value of pathological experiments. Br Med J 2: 198-203.

32. Abbasi A, Bhutto AR, Butt N, Munir SM (2012) Corelation of serum alpha fetoprotein and tumor size in hepatocellular carcinoma. J Pak Med Assoc 62: 33-36.

33. Maeda S, Kamata H, Luo JL, Leffert H, Karin M (2005) IKKbeta couples hepatocyte death to cytokine-driven compensatory proliferation that promotes chemical hepatocarcinogenesis. Cell 121: 977-990.
34. Karin M, Cao Y, Greten FR, Li ZW (2002) NF-kappaB in cancer: From innocent bystander to major culprit. Nat Rev Cancer 2: 301-310.

35. Gonzalez-Ramella O, Ortiz-Lazareno PC, Jimenez-Lopez X, GallegosCastorena S, Hernandez-Flores G, et al. (2016) Pentoxifylline during steroid window phase at induction to remission increases apoptosis in childhood with acute lymphoblastic leukemia. Clin Transl Oncol 18: 369-374.

36. Jie C, Guo YH, Zhang HY, Jiang LL, Ma JQ, et al. (2014) Cyclooxygenase-2 inhibitor is a robust enhancer of anticancer agents against hepatocellular carcinoma multicellular spheroids. Onco Targets Ther 7: 353-363.

37. Cervello M, Bachvarov D, Lampiasi N, Cusimano A, Azzolina A, et al. (2013) Novel combination of sorafenib and celecoxib provides synergistic anti-proliferative and pro-apoptotic effects in human liver cancer cells. PLoS One 8: e65569.

38. Kim JS, Park BR, Nam GH, Bae DH (2012) Synergistic effects of sorafenib and celecoxib inhibit growth and VEGF expression in Hec-1A endometrial cancer cell line. Korean J Obstet Gynecol 55: 814-821.

39. Ren F, Fan M, Mei J, Wu Y, Liu C, et al (2014) Interferon-gamma and celecoxib inhibit lung-tumor growth through modulating M2/M1 macrophage ratio in the tumor microenvironment. Drug Des Devel Ther 8: 1527-1538.

40. Cervello M, McCubrey JA, Cusimano A, Lampiasi N, Azzolina A, et al. (2012) Targeted therapy for hepatocellular carcinoma: Novel agents on the horizon. Oncotarget 3: 236-260.

41. Abu Dayyeh BK, Yang M, Fuchs BC, Karl DL, Yamada S, et al. (2011) A functional polymorphism in the epidermal growth factor gene is associated with risk for hepatocellular carcinoma. Gastroenterology 141: 141-149.

42. El-Khoueiry AB, Sangro B, Yau T, Crocenzi TS, Kudo M, et al. (2017) Nivolumab in patients with advanced hepatocellular carcinoma (CheckMate 040): an open-label, non-comparative, phase 1/2 dose escalation and expansion trial. Lancet. 389: 2492-2502.

43. Liu Y, Liu A, Li H, Li C, Lin J (2011) Celecoxib inhibits interleukin-6/ interleukin-6 receptor-induced JAK2/STAT3 phosphorylation in human hepatocellular carcinoma cells. Cancer Prev Res (Phila) 4: 1296-1305.

44. Leahy KM, Ornberg RL, Wang Y, Zweifel BS, Koki AT, et al. (2002) Cyclooxygenase- 2 inhibition by celecoxib reduces proliferation and induces apoptosis in angiogenic endothelial cells in vivo. Cancer Res 62: 625-631.

45. Ftahy MM, Latif NSA, Alalkamy EF, Batrawi FA, Gala HA (2013) Antifibrotic potential of a selective COX-2 inhibitor (celecoxib) on liver fibrosis in rats. Compar Clin Pathol 22: 425-430.

46. Bravo-Cuellar A, Ortiz-Lazareno PC, Lerma-Diaz JM, DominguezRodriguez JR, Jave-Suarez LF, et al. (2010) Sensitization of cervix cancer cells to Adriamycin by Pentoxifylline induces an increase in apoptosis and decrease senescence. Mol Cancer 9: 114. 